\title{
Adsorptive removal of chromium(VI) from aqueous solution using binary bio-polymeric beads made from bagasse
}

\author{
Harish Kumar ${ }^{1} \cdot$ Kanhaiya Lal Maurya $^{1} \cdot$ Avneesh Kumar Gehlaut ${ }^{1} \cdot$ Deepshikha Singh ${ }^{1} \cdot$ Sanjeev Maken $^{2}$. \\ Ankur Gaur ${ }^{1}$. Suantak Kamsonlian ${ }^{1}$
}

Received: 8 January 2019 / Accepted: 18 November 2019 / Published online: 2 December 2019

(c) The Author(s) 2019

\begin{abstract}
In this study, bio-polymeric gel beads were made from synthetic and laboratory-made CMC (bagasse). Calcium chloride cross-linked with sodium alginate (Na-Alg) added to CMC displayed great affinity for the removal of hexavalent chromium $(\mathrm{Cr}(\mathrm{VI}))$ ions present in an aqueous solution. Activated carbon obtained from bagasse was also used for adsorptive removal of $\mathrm{Cr}(\mathrm{VI})$ ions from aqueous solution. The effect of different adsorption parameters such as $\mathrm{pH}$, contact time and adsorbent dosage was studied. Bio-polymeric gel beads and activated carbon were prepared and characterized by SEM, FTIR and XRD. The maximum percentage removal for synthetic and bagasse bio-polymeric gel beads reaches $94.56 \%$ and $98.42 \%$ values at a pH of 4.0 at $25^{\circ} \mathrm{C}$ and for activated carbon $64.79 \%$ value at a pH of 6.0 at $25^{\circ} \mathrm{C}$. Higher degree of substitution results in an increase in the percentage removal of $\mathrm{Cr}(\mathrm{VI})$ ions due to the increase in the surface area and the binding sites of the adsorbent. Our study suggests that bio-polymeric gel beads made from laboratory-made CMC (bagasse) can be used in a more cost-effective and efficient way for the removal of harmful chromium ions.
\end{abstract}

Keywords Carboxymethyl cellulose $(\mathrm{CMC}) \cdot$ Sodium alginate $\cdot$ Gel beads $\cdot$ Activated carbon

\section{Introduction}

Heavy metals, widely used in industrial wastewater, are extremely toxic to human kidneys, liver, lungs and intestines. Discarded chromium $(\mathrm{Cr})$ is a general toxic heavy metal pollutant present in wastewater, where it basically exists in two stable oxidation states, i.e., trivalent chromium $(\mathrm{Cr}(\mathrm{III}))$ and hexavalent chromium $(\mathrm{Cr}(\mathrm{VI}))$. Chromium is widely used in industries like electroplating, leather tanning, ceramics, pigment manufacturing, ceramics, wood preservation and manufacturing of paper. Chromium is used in leather tanning process in large quantity to stop water diffusion inside leather pores. $\mathrm{Cr}(\mathrm{VI})$ is primarily present in the form of chromate $\left(\mathrm{CrO}_{4}{ }^{2-}\right)$ and dichromate $\left(\mathrm{CrO}_{7}{ }^{2-}\right)$ ions. On the other hand the $\mathrm{Cr}(\mathrm{VI})$ is also 500 times more

Ankur Gaur

ankur@mnnit.ac.in

1 Department of Chemical Engineering, Motilal Nehru National Institute of Technology, Allahabad, Prayagraj 211004, Uttar Pradesh, India

2 Deenbandhu Chhotu Ram State University of Science and Technology, Murthal, India toxic than the trivalent form (Garg et al. 2007; Fahim et al. 2006). $\mathrm{Cr}(\mathrm{VI})$ is a very soluble and toxic chromate anion and is a distrusted carcinogen and mutagen. The conventional physical and chemical methods used for the chromium removal from wastewater include reduction, solvent extraction, precipitation, ion exchange, membrane filtration, reverse osmosis and adsorption (Sathish et al. 2015). Precipitation process is favored, but the major drawback is sludge formation. Ion exchange is a better technique, but its operating cost is high. Cellulose is a linear and high molecular weight polymer, and due to the presence of inter- and intra-molecular -OH bond, it neither melts nor dissolves easily in common solvents and it can be chemically modified to increase its metal-binding ability (Yang et al. 2011; Selvi et al. 2001; Khezami and Capart 2005). Cellulose is highly crystalline in nature, and this high crystallinity results in low adsorption capacity for heavy metal ions such as chromium. Adsorption on bio-polymeric adsorbent made from CMC which is extracted from cellulose is an extremely effective way for the removal of heavy toxic metals because of low cost and high feasibility. Activated carbon is also efficient in the removal of heavy metals because of its low cost and easy regeneration of the carbon. $\mathrm{Cr}(\mathrm{VI})$ adsorption 
is dependent on $\mathrm{pH}$, and maximum removal takes place between $\mathrm{pH} 5$ and 6 for activated carbon. It is an amorphous solid involving of microcrystallites with a graphite lattice, and they are nonpolar, highly porous, usually equipped in powder form (Abdulrazak et al. 2017; Fahim et al. 2006). Natural bio-polymeric beads offer number of advantages such as nontoxic, inexpensive, renewable, biodegradable, modifiable, etc. This is an efficient method for the removal of heavy metals from wastewater. In this study, we focus on bio-polymeric gel beads made from carboxymethyl cellulose (CMC). CMC is a water-soluble polysaccharide formed by mercerization and etherification process. CMC displays alkaline solubility when the degree of substitution is about 0.3 and displays water solubility when the degree of substitution is above 0.4 (Kumar et al. 2018). CMC is highly amorphous in nature and has high adsorption capacity for heavy metal ions removal. CMC is widely used in oil exploration, detergents, cosmetics, paper products, food and textile industries. Synthetic CMC obtained directly from market offers 0.51 degree of substitution (DS), and laboratory-made CMC from bagasse has a DS of 0.65 (Gulati et al. 2014; Joshi et al. 2015; Mohkami and Talaeipour 2011). This higher DS of laboratory-made CMC results in better use in the commercial products (Yeasmin and Mondal 2015). Na-Alg is a natural polysaccharide biopolymer mainly composed of mannuronic and guluronic acid and contains free carboxyl groups which make it attractive addition to CMC. Alginate can be cross-linked with several divalent and trivalent cations (i.e., $\mathrm{Ca}, \mathrm{Ba}$ and $\mathrm{Fe}$ ) to form a stable gel (Pourjavadi et al. 2006; Ren et al. 2016). The main objective of the current study is to calculate the adsorption capacity of bio-polymeric gel beads made from synthetic CMC and laboratory-made CMC (bagasse) and activated carbon obtained from bagasse waste for the efficient removal of $\mathrm{Cr}(\mathrm{VI})$ from the aqueous solution by varying the $\mathrm{pH}$, adsorbent dosage and contact time. The bio-polymer gel beads obtained were characterized and analyzed by infrared spectroscopy (FTIR), scanning electron microscopy (SEM) and X-ray diffraction analysis.

\section{Materials and methods}

\section{Raw material}

The chemicals used to make bio-polymeric beads were synthetic CMC having high molecular weight $\left(M_{\mathrm{w}}=10,000 \mathrm{Da}\right.$, $\mathrm{DS}=0.51)$ that was obtained from Molychem. We manufactured the CMC from bagasse ( $D S=0.65)$. All the other chemicals used were of analytical grade.

\section{Cellulose isolation from bagasse waste}

\section{Removal of moisture and reduction in size}

First, half kilogram of bagasse was dry in distilled water for $24 \mathrm{~h}$ to eliminate water-soluble extractives and dried in an oven at $75^{\circ} \mathrm{C}$ for 2 days. Afterward, bagasse was grind to pass through a 60 -mesh size screen.

\section{Acid hydrolysis}

Dilute sulfuric acid $(4 \% \mathrm{v} / \mathrm{v})$ can lead to the enzymatic biomass hydrolysis to eliminate hemicelluloses sugars through stirred at the temperature of $80{ }^{\circ} \mathrm{C}$ for $2 \mathrm{~h}$. The treated fibers were washed with Millipore water to attain $\mathrm{pH}$ 7. The filtered bagasse fibers were dried in an oven at $70.0{ }^{\circ} \mathrm{C}$ temperature.

\section{Alkali treatment}

$2 \% \mathrm{NaOH}$ was fed to the reactor at $80.0{ }^{\circ} \mathrm{C}$ to temperature for $2 \mathrm{~h}$ to enhance the swelling of the inner surface and reduces crystallinity and lignin structure disturbance. The treated fibers were filtered and washed with Millipore water to attain $\mathrm{pH} 7$. The filtered bagasse fibers were dried in an oven at $70.0^{\circ} \mathrm{C}$ temperature.

\section{Bleaching}

Whiteness was obtained by using sodium chlorite (4\% w/v) at $80.0^{\circ} \mathrm{C}$ for $4 \mathrm{~h}$. The $\mathrm{pH}$ maintained during bleaching process was within 3-4 adjusted by adding acetic acid drop by drop. After washing, cellulose fibers were dried in an oven at $70{ }^{\circ} \mathrm{C}$ temperature.

\section{Production of CMC from cellulose}

The cellulose produced from bagasse was dried in an oven for $1 \mathrm{~h}$ at $70.0^{\circ} \mathrm{C}$ temperature, and after that, it was placed in the desiccator to avoid moisture. There are two steps for the production of CMC mercerization followed by etherification.

\section{Mercerization}

In total, $100 \mathrm{ml}$ isopropanol in $100 \mathrm{ml}$ of $20 \% \mathrm{w} / \mathrm{v} \mathrm{NaOH}$ solution was mixed with 10 grams of cellulose sample that helps to break the inter- and intra-molecular - $\mathrm{OH}$ bonding. The mixture was stirred for $2.5-4 \mathrm{~h}$ and increased the temperature from 50.0 to $60.0^{\circ} \mathrm{C}$. The washed alkali cellulose 
fibers were filtered and dried in an oven for 3-4 $\mathrm{h}$ s at $70.0^{\circ} \mathrm{C}$, and then, it was sent for etherification process.

\section{Etherification}

In total, $100 \mathrm{ml}$ of $20 \%$ MCA (monochloroacetic acid) solution was mixed with mercerized cellulose and stirred for 2.5-4 h from 50 to $60{ }^{\circ} \mathrm{C}$ to support and substitute the $-\mathrm{OH}$ groups with the $\mathrm{CH}_{2} \mathrm{COOH}$ groups. After etherification reaction, it was filtered and washed with $\mathrm{HCl}$ and ethanol mixture (mixed in equal volume). $\mathrm{HCl}$ causes neutralization of any $\mathrm{NaOH}$ remaining, and ethanol removes salt formed during the side reaction. The remaining residue on filter paper was the $\mathrm{CMC}$ produced which was then dried in an oven at $60.0{ }^{\circ} \mathrm{C}$ temperature for $12 \mathrm{~h}$ (Gulati et al. 2014; Kumar et al. 2009). The complete schematic representation of synthesis of carboxymethyl cellulose from cellulose is displayed in Scheme 1.

\section{Preparation of bio-polymeric beads}

The polymer beads were prepared by using both CMCs (synthetic and laboratory made) and sodium alginate ( $0.5 \mathrm{~g}$ each) by mixing in $100 \mathrm{ml}$ of distilled water. To form granular beads $0.05 \mathrm{M} \mathrm{CaCl}_{2}$ was added in the mixture which acted as cross-linking agent, thus helping in the formation of gelting beads with constant slow stirring. After $24 \mathrm{~h}$, gelatin beads were removed and washed with distilled water with number of times to make it free from several unreacted ions. Afterward the polymeric beads were stored in distilled water at room temperature. The whole process of preparation of biopolymeric gel beads from laboratory-made CMC is shown in Fig. 1.

\section{Preparation of activated carbon from bagasse waste}

Activated carbon was prepared from sugarcane bagasse waste under nitrogen atmosphere. The pyrolysis of waste was done at $800{ }^{\circ} \mathrm{C}$. After pyrolysis, the char was soaked with potassium hydroxide $(\mathrm{KOH})$ and mixture was dried overnight at $90^{\circ} \mathrm{C}$. The produced activated carbon was transferred to a beaker containing hydrochloric acid $(0.1 \mathrm{~mol} / \mathrm{l})$ (to remove inorganic compounds), stirred for $1 \mathrm{~h}$ and then washed with warm deionized water to remove residual $\mathrm{HCl}$, until the $\mathrm{pH}$ of the solution neutralized and then filtered. The filtered activated carbon was dried in an oven at $90{ }^{\circ} \mathrm{C}$ overnight (Eslami et al. 2018).

\section{Preparation of the chromium solution}

Chromium solutions of $1000 \mathrm{mg} / \mathrm{dm}^{-3}$ were prepared by dissolving $0.245 \mathrm{mg} \mathrm{K}_{2} \mathrm{Cr}_{2} \mathrm{O}_{7}$ in $1000 \mathrm{ml}$ of double-distilled water. The required operational solutions of different concentrations were prepared by proper dilution of the stock<smiles>CCOC(O)C(O)C(O)OC(C)CO</smiles>

Cellulose

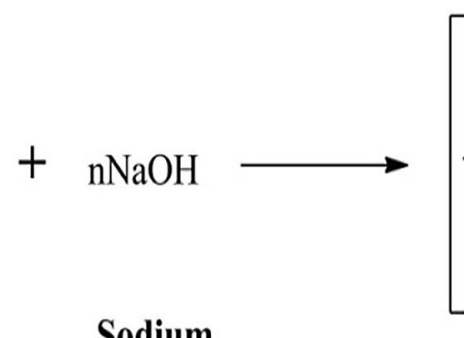

Sodium

hydroxide

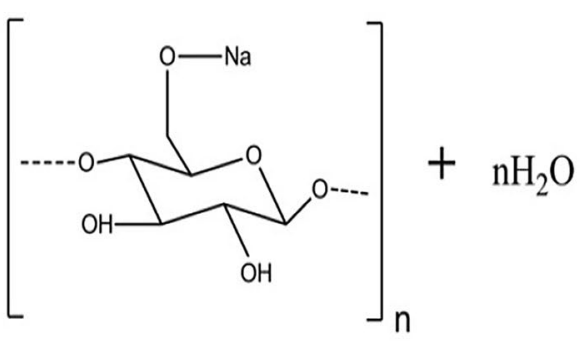

Mercerized Cellulose

Water

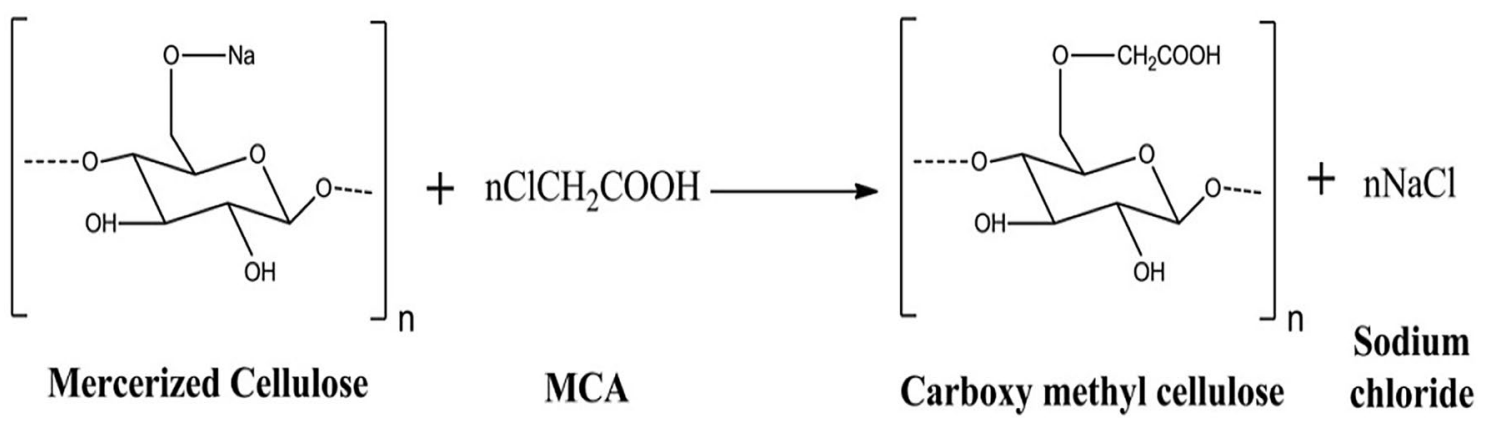

Scheme 1 Synthesis of carboxymethyl cellulose from cellulose 


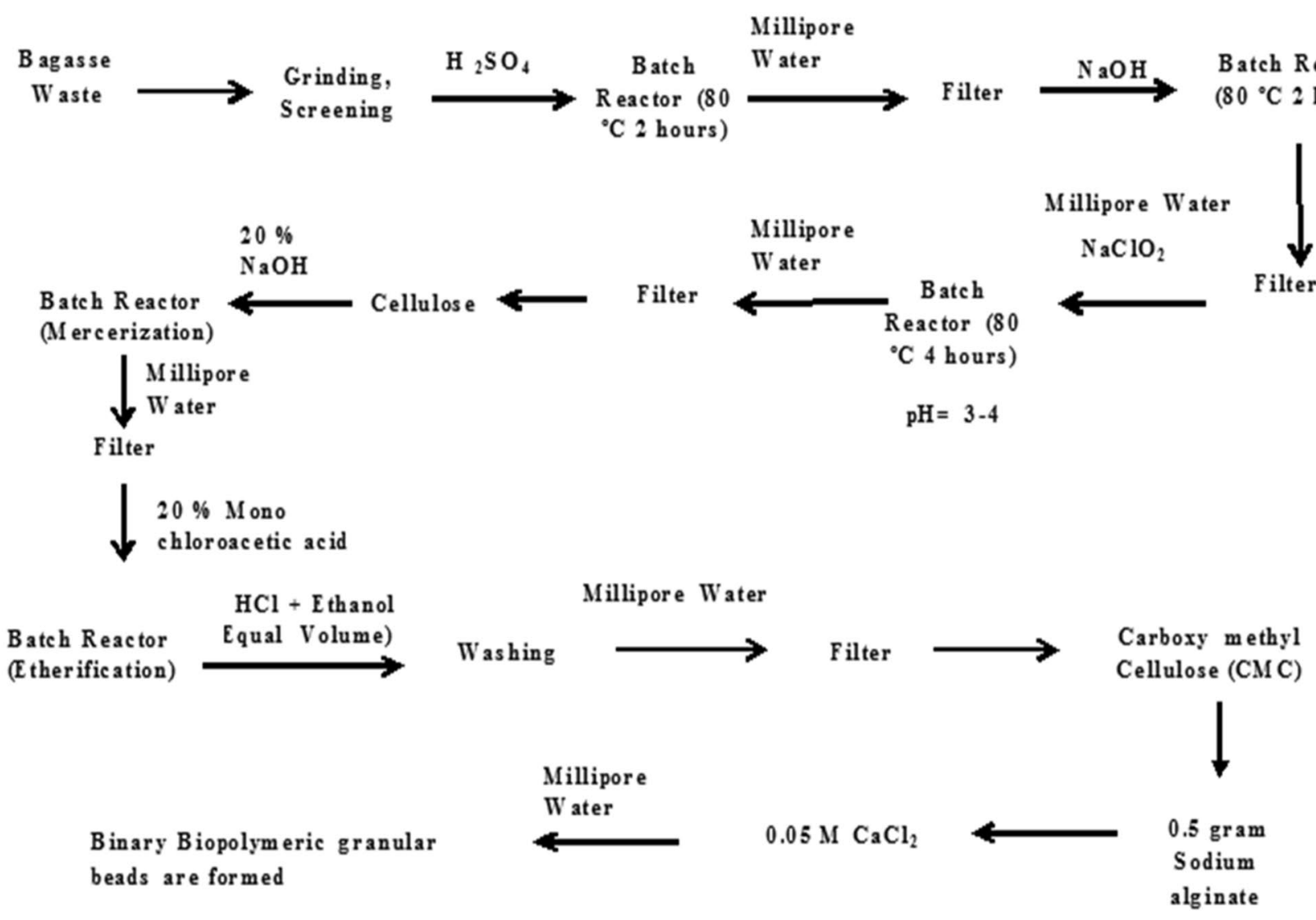

Fig. 1 Preparation of bio-polymeric beads from laboratory-made CMC

solution. The reagent was prepared by dissolving $0.2 \mathrm{~g}$ diphenyl carbazide in ethyl alcohol and sulfuric acid (1:2) concentration. After that the reagent was stored in amber bottle to avoid light.

\section{Batch mode adsorption studies}

For each experiment $0.2 \mathrm{~g}$ bio-polymeric gel beads and $0.3 \mathrm{~g}$ activated carbon quantity of the adsorbent were introduced into 100-ml stoppered conical flasks in which $20 \mathrm{ml}$ of the potassium dichromate solution was added. The desired $\mathrm{pH}$ values $(2,4,6,8,10)$ were maintained by the addition of $0.01 \mathrm{M}$ hydrochloric acid $(\mathrm{HCl})$ and $\mathrm{NaOH}$ solution. The solution was kept in a temperature-controlled shaker at a steady speed of $150 \mathrm{rpm}$ for a period of $(5,10,15,20$, 25) min at room temperature to achieve the equilibrium. After the required time, samples were taken from the incubator and the adsorbent was separated by filtration and the supernatant was centrifuged for $5 \mathrm{~min}$. The residual chromium ion concentration was determined by diphenyl carbazide method. After that, the absorbance was calculated with the help of UV-Vis spectrophotometer (PerkinElmer, Shimadzu, Japan). The purple-violet color complex solution recorded a peak at $540 \mathrm{~nm}$. The quantity of chromium adsorbed per unit weight of adsorbent, $q_{\mathrm{e}}(\mathrm{mg} / \mathrm{g})$, was calculated by following Eq. (1):

$q_{\mathrm{e}}=\frac{\left(C_{0}-C_{\mathrm{e}}\right) V}{W}$

where $V$ is the volume (L) of $\mathrm{Cr}(\mathrm{VI})$ solution, $C_{0}$ and $C_{\mathrm{e}}$ are the initial and equilibrium concentrations $(\mathrm{mg} / \mathrm{L})$ of $\mathrm{Cr}(\mathrm{VI})$ in solution, respectively, and $W$ is the weight $(\mathrm{g})$ of adsorbent.

\section{Characterization of adsorbent}

Fourier Transform infrared spectroscopy (FTIR) indicates chemical occurring in the bio-polymer. For analysis the samples were crushed with KBR to make pellets, and spectra were taken on PerkinElmer $B_{X} 11-F T I R$ Spectrophotometer, in the range of $4000-400 \mathrm{~cm}^{-1}$. The surface morphology of the bio-polymeric beads and activated carbon was examined using scanning electron microscopy (SEM). The dried samples were layered with a thin layer of palladium gold alloy after mounting on a twice sided carbon tape (Zeiss 1555 VP). The dried samples were compressed into the disks and then measured with an X-ray diffractometer models recorded 
with Rigaku D/MAX-2400 X-ray diffractometer system using a $\mathrm{Cu}$ Ka radiation $\left(11 \frac{1}{4} 1.5406 \AA\right)$ in the $2 q$ range from $5^{\circ}$ to $70^{\circ}$, operated at $40 \mathrm{~mA}$ and $40 \mathrm{kV}$, and a scanning speed of $10^{\circ} / \mathrm{min}$.

\section{Results and discussion}

\section{Effect of $\mathrm{pH}$ on removal}

The $\mathrm{pH}$ plays an important role in the removal of heavy metal ions present in an aqueous solution. The $\mathrm{pH}$ also affects the degree of ionization of the adsorbent, solubility of metal ions and charge present on the adsorption sites. To determine the effect of $\mathrm{pH}$ in the removal of chromium ions, it was varied from 2 to 10 . The maximum adsorption of $\mathrm{Cr}(\mathrm{VI})$ ions occurred at $\mathrm{pH} 4$, and adsorption decreased at higher or lower $\mathrm{pH}(2$ and 6$)$. At $\mathrm{pH} 2$ the adsorption removal of the metal ion was lower as compared to $\mathrm{pH} 4$ due to the acidic nature of chromium solution, because at $\mathrm{pH} 2$ protonation increases $\mathrm{H}^{+}$ions which results in decrease in the adsorption capacity due to elimination of electrostatic repulsive forces. With an increase in $\mathrm{pH}$ from 4 to 7 , deprotonation occurs and it results in decrease in electrostatic repulsive forces. There are many carboxylic groups present in bio-polymeric gel beads that increase the adsorption efficiency at pH 4 (Yang et al. 2011; Dewangan et al. 2011). In activated carbon with an increase in $\mathrm{pH}$ from 4 to 10 degree of protonation decreases resulting in electrostatic forces elimination (Murugesan et al. 2012). The percentage removal of $\mathrm{Cr}(\mathrm{VI})$ ions for synthetic and sugarcane bagasse bio-polymeric gel bead reaches maximum $94.56 \%$ and $98.42 \%$ values at a pH of 4.0 at $25^{\circ} \mathrm{C}$ and for activated carbon $64.79 \%$ value at a pH of 6.0 at $25^{\circ} \mathrm{C}$ as shown in Fig. 2 .

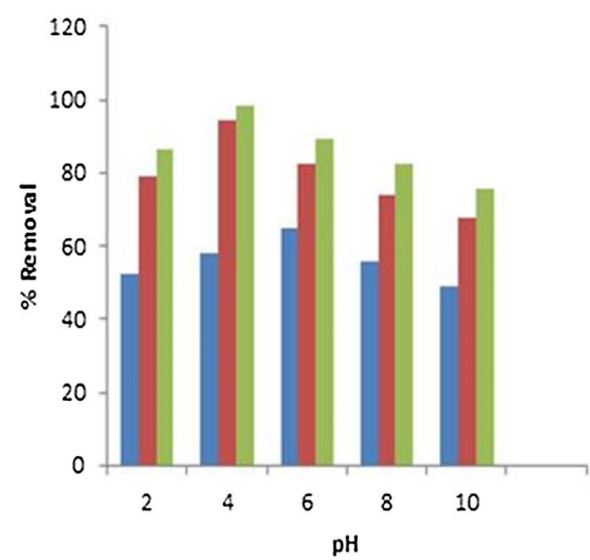

activated carbon

USynthetic gel bead

Inagasse gel be ad

Fig. 2 Effect of $\mathrm{pH}$ on the adsorption of chromium ions onto biopolymer beads and activated carbon $=0.2,0.3 \mathrm{~g}, \mathrm{pH}=4.6$, temperature $=25^{\circ} \mathrm{C}$

\section{Effect of time on removal}

The adsorption experiments were monitored at different time intervals ( $0-25 \mathrm{~min})$ at $\mathrm{pH} 4$ and 6 for bio-polymeric gel beads and activated carbon using a constant concentration of chromium ions. In Fig. 3, it was found that as the time increases from 5 to 20 min adsorption removal increases and is almost constant after $15 \mathrm{~min}$ for bagasse and synthetic gel beads due to difference in the degree of substitution (DS) of bagasse $(0.65)$ and synthetic gel beads $(0.51)$. Higher degree of substitution (DS) increases the percentage removal of $\mathrm{Cr}(\mathrm{VI})$ ions due to an increase in the surface area and the binding sites of the adsorbent. In activated carbon the rate of removal increases

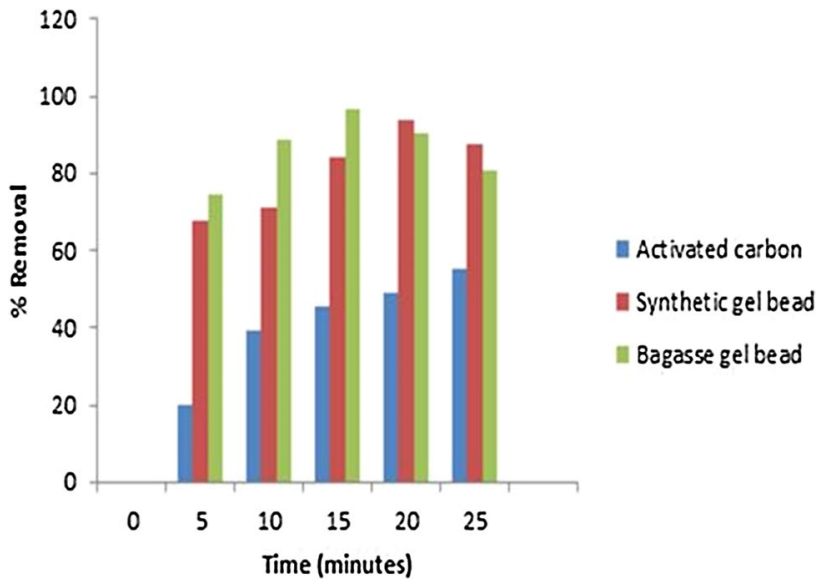

Fig. 3 Effect of time on the adsorption of chromium ions onto biopolymer beads and activated carbon $=0.2,0.3 \mathrm{~g}, \mathrm{pH}=4.6$, temperature $=25^{\circ} \mathrm{C}$

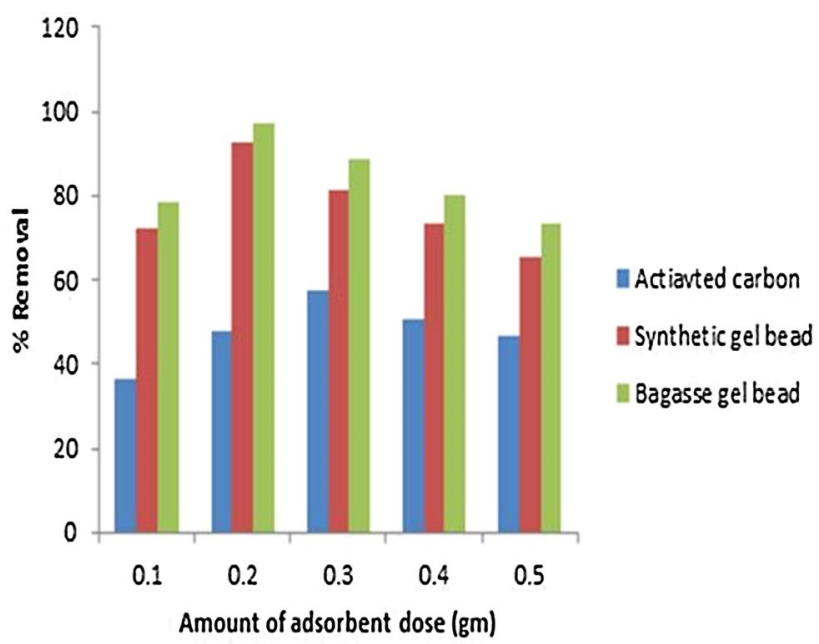

Fig. 4 Effect of adsorbent dose on the adsorption of chromium ions onto bio-polymer beads and activated carbon $=0.2,0.3 \mathrm{~g}, \mathrm{pH}=4.6$, temperature $=25^{\circ} \mathrm{C}$ 
as the time increases from 5 to $25 \mathrm{~min}$ due to availability of large number of free void sites of adsorbent for chromium ion adsorption (Murugesan et al. 2012; Dewangan et al. 2011).

\section{Effect of adsorbent dosage}

The adsorbent dosage is also an important parameter for the heavy metal ions adsorption. Variation in adsorption dosage of bio-polymeric gel beads affects active sites of the adsorbent. As mentioned in Fig. 4, maximum $\mathrm{Cr}$ ions adsorption occurs at $0.2 \mathrm{~g}$ adsorption concentration in case of bio-polymeric gel beads. The adsorption capacity decreases after $0.2 \mathrm{~g}$ due to reduction in active sites on gel beads. Bagasse bio-polymeric gel beads show higher percentage removal and then synthetic bio-polymer gel beads and activated carbon because laboratory-made CMC (sugarcane bagasse) has high degree of substitution that increases surface area and porosity, hence increasing active sites for
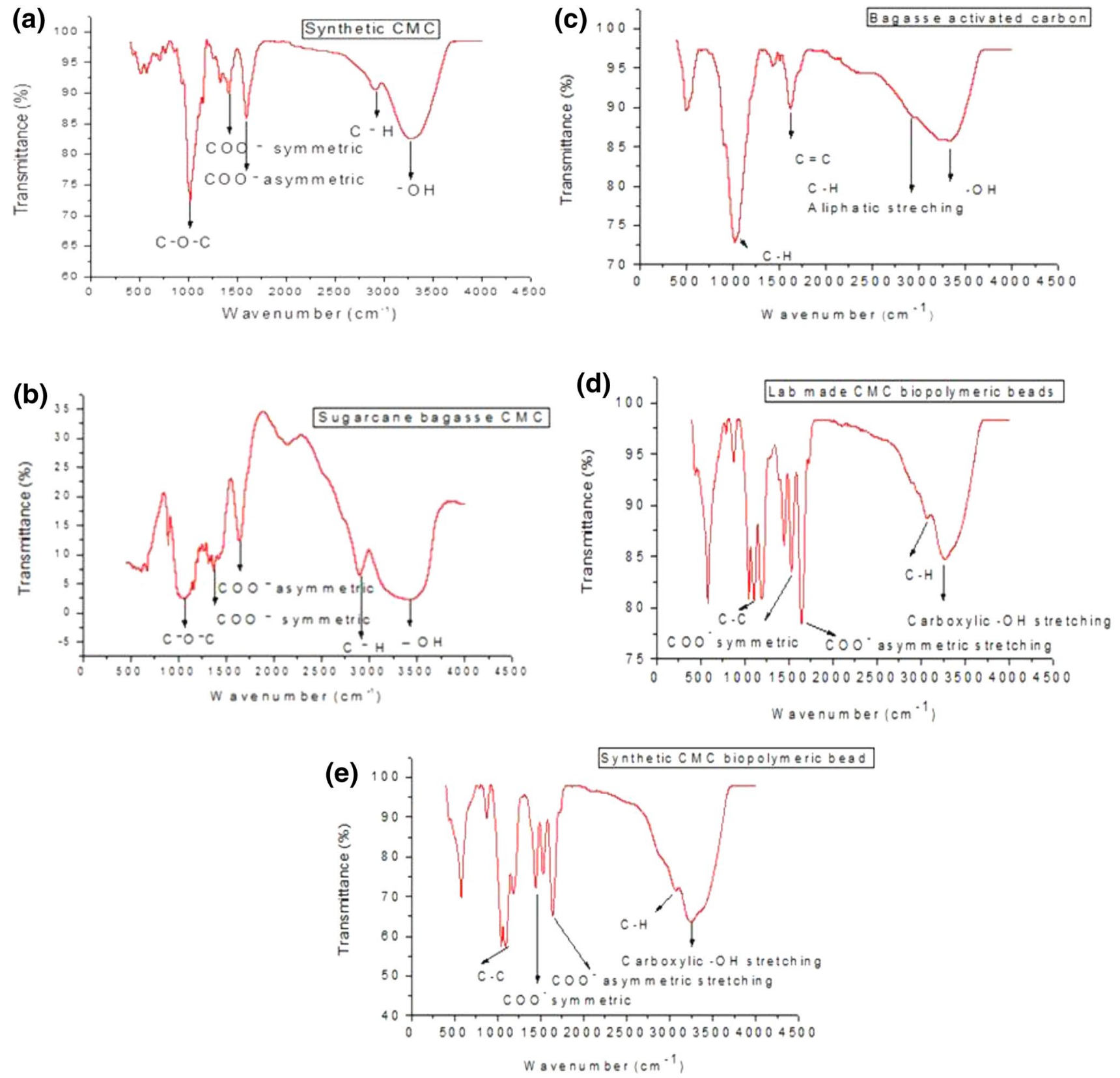

Fig. 5 a FTIR spectra of synthetic CMC, b FTIR spectra of bagasse CMC, $\mathbf{c}$ FTIR spectra of bagasse activated carbon, $\mathbf{d}$ FTIR spectra of biopolymeric beads of bagasse CMC and e FTIR spectra of bio-polymeric beads of synthetic CMC 
adsorption (Dewangan et al. 2011). In activated carbon chromium ions adsorption increases from 0.1 to $0.3 \mathrm{~g}$ and after that it starts decreasing because the number of availability of the exchangeable binding sites for adsorption decreases (Murugesan et al. 2012).

\section{FTIR spectroscopy}

Figure 5a-e shows the FTIR spectrum of CMC (Rachtanapun and Rattanapanone 2011; Saputra et al. 2014), biopolymeric gel beads (Dewangan et al. 2011) and activated carbon (Hesas et al. 2013; Takahata et al. 2009). The distinct difference is observed between CMC, bio-polymeric gel beads and activated carbon. The band at range 3300-3400 $\left(\mathrm{cm}^{-1}\right)$ is assigned to the $-\mathrm{OH}$ stretching vibrations. The band observed at range 2700-2900 $\left(\mathrm{cm}^{-1}\right)$ in the spectrum of CMC, bio-polymeric gel beads and activated carbon indicates the $-\mathrm{CH}$ aliphatic stretching. It can be seen from the spectrum that the band at range $1500-1650\left(\mathrm{~cm}^{-1}\right)$ indicates the $\mathrm{C}-\mathrm{O}$ stretching, asymmetrical stretching $-\mathrm{COO}^{-}, \mathrm{C}=\mathrm{C}$ stretching for CMC, bio-polymeric gel beads and activated carbon. The band observed at range 1300-1500 $\left(\mathrm{cm}^{-1}\right)$ indicates the $-\mathrm{CH}_{2}$ bonding, symmetrical stretching, $-\mathrm{C}-\mathrm{H}$ aliphatic bending for CMC, bio-polymeric gel beads and activated carbon. The band at $1000-1150\left(\mathrm{~cm}^{-1}\right)$ indicates the $\mathrm{C}-\mathrm{O}-\mathrm{C}$ stretching, $\mathrm{C}-\mathrm{O}-\mathrm{C}$ stretching, $\mathrm{O}-\mathrm{H}$ stretching for $\mathrm{CMC}$, bio-polymeric gel beads and activated carbon. The band observed at $833,856,865$ indicates the $\beta$-glycoside linkage, $\mathrm{C}-\mathrm{C}$ stretching, $\mathrm{C}-\mathrm{C}$ stretching for $\mathrm{CMC}$, bio-polymeric gel beads and activated carbon. The functional groups present on the surface of adsorbent identified by FTIR are summarized in Table 1.

\section{XRD analysis}

$\mathrm{X}$-ray diffraction (XRD) was performed to investigate the crystallinity of CMC, bio-polymeric gel beads and activated carbon shown in Fig. 6a-c. In CMC structure XRDtype peak's height and width were significantly changed due to breaking of the $-\mathrm{OH}$ bond that maintained the crystalline arrangement by replacing hydrogen atoms of -OH by carboxymethyl groups (Gulati et al. 2014). The
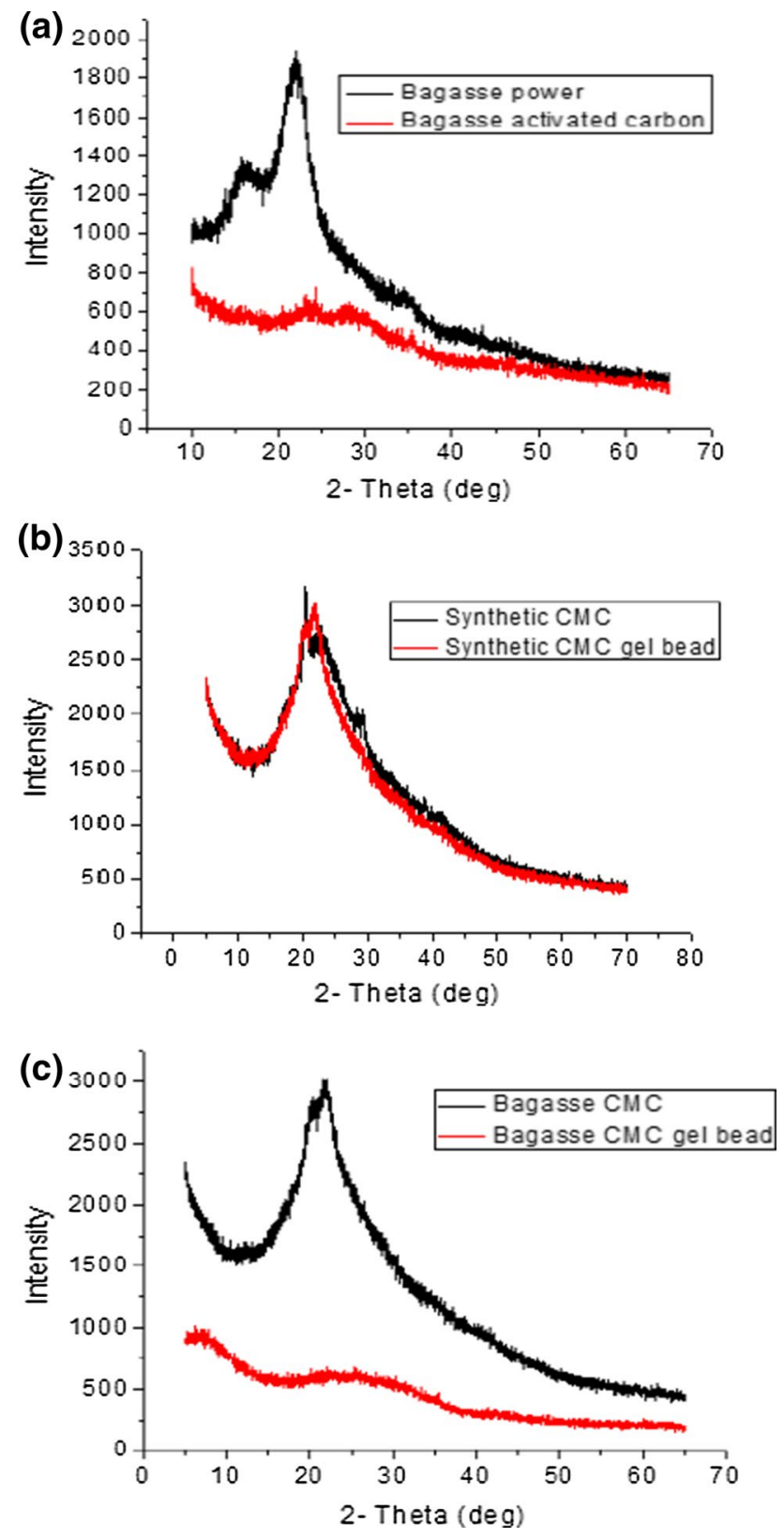

Fig. 6 a XRD spectra of bagasse powder and activated carbon, b XRD spectra of synthetic CMC and synthetic CMC bio-polymeric gel bead and $\mathbf{c}$ XRD spectra of bagasse CMC and bagasse CMC biopolymeric gel bead

Table 1 Functional group of CMC, polymeric gel bead and activated carbon

\begin{tabular}{llll}
\hline Wave number $\left(\mathrm{cm}^{-1}\right)$ & Bands indication of CMC & Bands indication of polymeric gel & Bands indication of activated carbon \\
\hline $3300-3400\left(\mathrm{~cm}^{-1}\right)$ & O-H stretching & Carboxylic $-\mathrm{OH}$ stretching & O-H stretching \\
$2700-2900\left(\mathrm{~cm}^{-1}\right)$ & $-\mathrm{CH}$ aliphatic stretching & $-\mathrm{CH}$ aliphatic stretching & $\mathrm{C}-\mathrm{H}$ aliphatic stretching \\
$1500-1650\left(\mathrm{~cm}^{-1}\right)$ & $\mathrm{C}-\mathrm{O}$ stretching of carboxyl group & Asymmetrical stretching $-\mathrm{COO}^{-}$ & $\mathrm{C}=\mathrm{C}$ stretching band \\
$1300-1500\left(\mathrm{~cm}^{-1}\right)$ & $\mathrm{CH}_{2}$ bonding & Symmetrical stretching $-\mathrm{COO}^{-}$ & $-\mathrm{C}-\mathrm{H}$ aliphatic bending \\
$1000-1150\left(\mathrm{~cm}^{-1}\right)$ & $\mathrm{C}-\mathrm{O}-\mathrm{C}$ stretching & $\mathrm{C}-\mathrm{O}-\mathrm{C}$ stretching & $\mathrm{C}-\mathrm{O}$ carboxylic acid, alcohols, esters \\
\hline & & &
\end{tabular}


decrease in crystallinity is significant in many applications, like manufacturing of hydrogels, enhanced ability of $\mathrm{CMC}$ to absorb water due to an increase in the amorphous region (Spychaj et al. 2013). Crystalline peak in XRD spectra of CMCs gets shifted due to the breakage of $\beta-1$, 4 glycosidic bonding which is responsible for increase in (a)

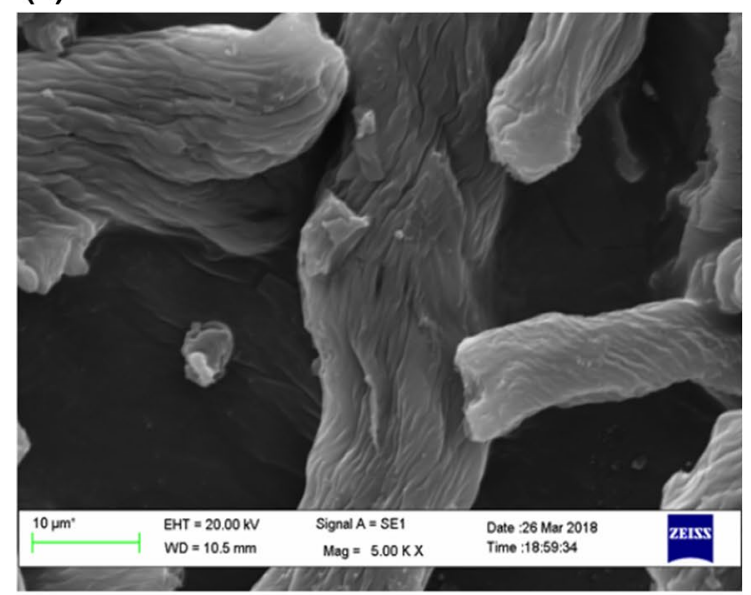

(b)

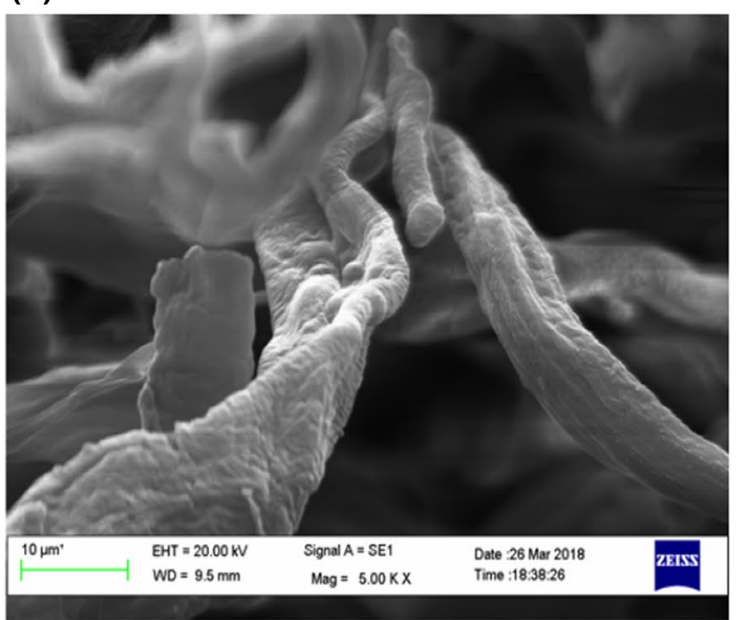

(c)

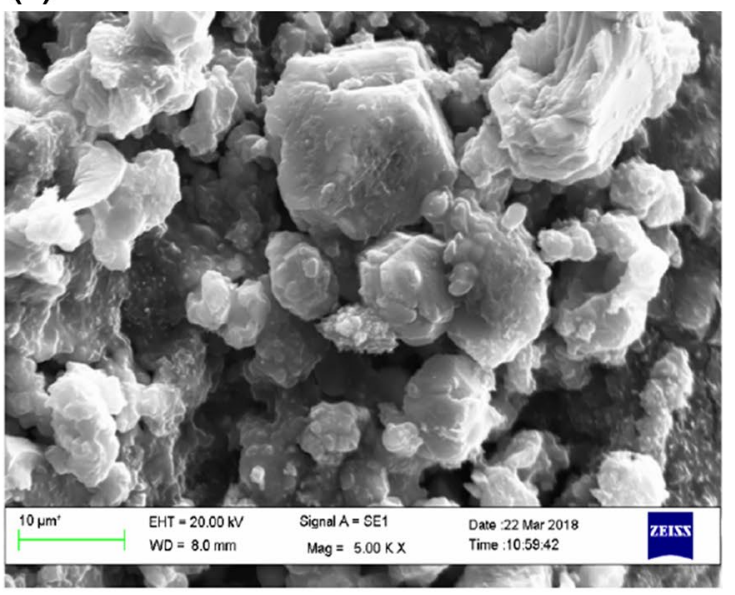

(d)

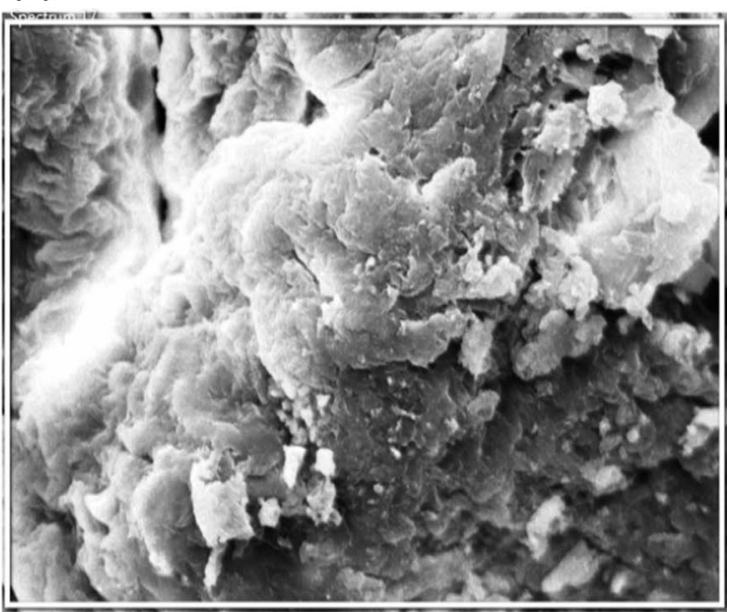

(e)

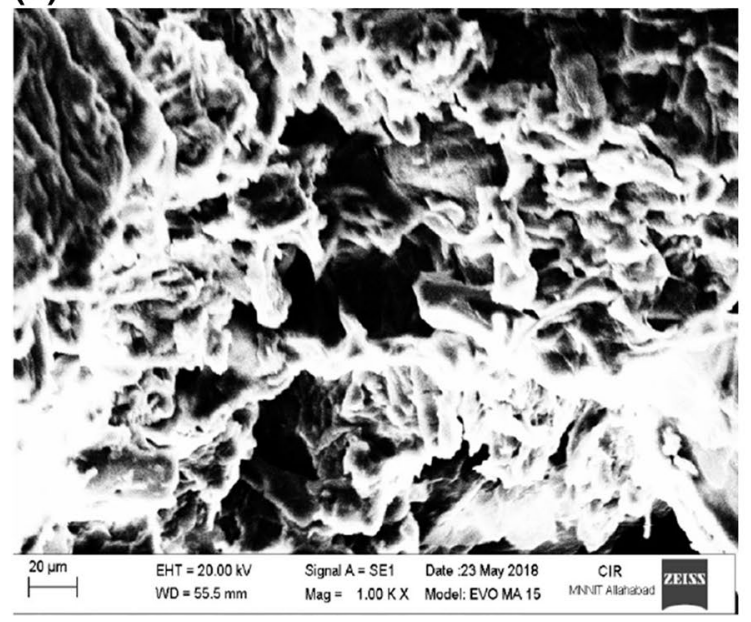

Fig. 7 a SEM of synthetic CMC, b SEM of laboratory-made CMC (bagasse), c SEM of bio-polymer gel bead made from laboratory-made CMC (bagasse), d SEM of bio-polymer gel bead made from synthetic CMC and e SEM of bagasse activated carbon 
the gap among cellulose molecules. Bio-polymeric gel bead diffraction signals at $2 \theta=15^{\circ}, 17.8^{\circ}, 22.8^{\circ}$ were not observed in the XRD spectra, because of the presence of cross-linking between the sodium alginate, and calcium chloride could destroy the crystallinity and increase the amorphous region. Due to the lack of crystallinity, metal ions could easily penetrate into the gel beads and hence increase in adsorption capacity occurs (Yang et al. 2011). The diffraction peak at the position of $2 \theta=23^{\circ}$ shows the amorphous region of the activated carbon because $\mathrm{KOH}$ activation increases the specific surface area of porous carbon materials and decreases the crystallinity of the structure (Takahata et al. 2009).

\section{Morphological analysis}

The SEM image was employed to investigate the surface morphology of CMC, bio-polymer gel beads and activated carbon structures as shown in Fig. 7a-e. The higher concentration of $\mathrm{NaOH}$ during mercerization hydrolyzed the remaining hemicellulose that increases the surface area for better contact during etherification process (MCA) (Gulati et al. 2014). The higher the DS values more cracks will appear because during the carboxymethylation reaction disruption of the outer layer of the cellulose fibers occurs (Gu et al. 2012). Bio-polymeric gel beads surface was moderately rough surface and exhibited more porosity. This porosity is due to the electrostatic repulsions among the carboxylate anions $\left(\mathrm{COO}^{-}\right)$which increases the size of pores in the gel beads (Pourjavadi et al. 2006). Therefore, metal ions can simply disperse in and out and hence increases the adsorption capacity of the adsorbent. The bagasse raw material was fairly smooth with few cracks or voids. After the activation with $\mathrm{KOH}$ carbonization increases the size of the pores and also decomposition of the volatile organic matters happens (Eslami et al. 2018).

\section{Conclusion}

In this study bio-polymeric gel beads manufactured from synthetic and laboratory-made CMC (bagasse) and sodium alginate show great promise as an adsorbent for the removal of chromium ions. The $\mathrm{pH}$ also affects degree of ionization of the adsorbent, solubility of metal ions and charge present on the adsorption sites. An increase in $\mathrm{pH}$ hikes the adsorption capacity due to de-protonation (reduction of $\mathrm{H}^{+}$ions) of the metal-binding sites. Activated carbon made from bagasse also displays high chromium percentage $(64 \%)$ removal, but it is much lower than synthetic gel beads and bagasse gel beads $(94.56 \%)$ and $(98.45 \%)$. Gel beads concentration also effects the $\mathrm{Cr}(\mathrm{VI})$ removal. Bagasse bio-polymeric gel bead shows higher percentage removal than synthetic biopolymer gel bead and activated carbon because laboratorymade CMC (bagasse) has higher degree of substitution that increases surface area and porosity and hence provides more active sites for adsorption. This porosity is due to the electrostatic repulsions among the carboxylate anions $\left(\mathrm{COO}^{-}\right)$ which increases the size of pores in the gel beads. This study provides an economical, easily available adsorbent for the removal of chromium ions from the aqueous solutions.

Acknowledgements We greatly acknowledge the support of CIR, MNNIT, Allahabad, and department of physics, Allahabad University, for permitting us to use analytical instruments.

Open Access This article is distributed under the terms of the Creative Commons Attribution 4.0 International License (http://creativeco mmons.org/licenses/by/4.0/), which permits unrestricted use, distribution, and reproduction in any medium, provided you give appropriate credit to the original author(s) and the source, provide a link to the Creative Commons license, and indicate if changes were made.

\section{References}

Abdulrazak S, Hussaini K, Sani HM (2017) Evaluation of removal efficiency of heavy metals by low-cost activated carbon prepared from African palm fruit. Appl Water Sci 7:3151-3155

Dewangan T, Tiwari A, Bajpai AK (2011) Removal of chromium(VI) ions by adsorption onto binary biopolymeric beads of sodium alginate and carboxymethyl cellulose. J Dispers Sci Technol 32:1075-1082

Eslami A, Borghei SM, Rashidi A, Takdastan A (2018) Preparation of activated carbon dots from sugarcane bagasse for naphthalene removal from aqueous solutions. Sep Sci Technol. https://doi. org/10.1080/01496395.2018.1462832

Fahim NF, Barsoum BN, Eid AE, Khalil MS (2006) Removal of chromium(III) from tannery wastewater using activated carbon from sugar industrial waste. J Hazard Mater 136:303-309

Garg UK, Kaur MP, Garg VK, Sud D (2007) Removal of hexavalent chromium from aqueous solution by agricultural waste biomass. J Hazard Mater 140:60-68

Gu H, He J, Huang Y, Guo Z (2012) Fabrication of oxidized sodium carboxymethylcellulose from viscose fibers and their viscosity behaviors. Fibers Polym 14(8):1266-1270

Gulati I, Park J, Maken S, Lee MG (2014) Production of carboxymethylcellulose fibers from waste lignocellulosic sawdust using $\mathrm{NaOH} / \mathrm{NaClO}_{2}$ pretreatment. Fibers Polym 15(4):680-686

Hesas RH, Arami-Niya A, Sahu JN (2013) Preparation and characterization of activated carbon from apple waste by microwaveassisted phosphoric acid activation: application in methylene blue adsorption. Bioresources 8(2):2950-2966

Joshi G, Naithani S, Varshney VK, Bisht SS, Rana V, Gupta PK (2015) Synthesis and characterization of carboxymethyl cellulose from office waste paper: a greener approach towards waste management. Waste Manag 38:33-40

Khezami L, Capart R (2005) Removal of chromium(VI) from aqueous solution by activated carbons: Kinetic and equilibrium studies. J Hazard Mater 123:223-231

Kumar P, Barrett DM, Delwiche MJ (2009) Methods for pretreatment of lignocellulosic biomass for efficient hydrolysis and biofuel production. Ind Eng Chem Res 48:3713-3729

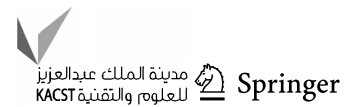


Kumar H, Gaur A, Kumar S, Park JW (2018) Development of silver nanoparticles-loaded CMC hydrogel using bamboo as a raw material for special medical applications. Chem Pap 73:953-964

Mohkami M, Talaeipour M (2011) Investigation of the chemical structure of carboxylated and carboxymethylated fibres from waste paper via XRD and FTIR analysis. Bioresources 6(2):1988-2003

Murugesan A, Vidhyadevi T, Kirupha SD, Ravikumar L, Sivanesan S (2012) Removal of chromium(VI) from aqueous solution using chemically modified corncorb-activated carbon: equilibrium and kinetic studies. Environ Prog Sustain Energy 32:673-680

Pourjavadi A, Barzegar Sh, Mahdavinia GR (2006) MBA-crosslinked $\mathrm{Na}-\mathrm{Alg} / \mathrm{CMC}$ as a smart full-polysaccharide superabsorbent hydrogels. Carbohyd Polym 66:386-395

Rachtanapun P, Rattanapanone N (2011) Synthesis and characterization of carboxymethyl cellulose powder and films from Mimosa pigra. J Appl Polym Sci 122:3218-3226

Ren H, Gao Z, Wu D, Jiang J, Sun Y, Luo C (2016) Efficient Pb(II) removal using sodium alginate-carboxymethyl cellulose gel beads: preparation, characterization, and adsorption mechanism. Carbohydr Polym 137:402-409

Saputra AH, Qadhayna L, Pitaloka AB (2014) Synthesis and characterization of carboxymethyl cellulose (CMC) from water hyacinth using ethanol-isobutyl alcohol mixture as the solvents. Int J Chem Eng Appl 5(1):36-40

Sathish T, Vinithkumar NV, Dharani G, Kirubagaran R (2015) Efficacy of mangrove leaf powder for bioremediation of chromium(VI) from aqueous solutions: kinetic and thermodynamic evaluation. Appl Water Sci 5:153-160

Selvi K, Pattabhi S, Kadirvelu K (2001) Removal of Cr(VI) from aqueous solution by adsorption onto activated carbon. Bioresour Technol 80:87-89

Spychaj T, Wilpiszewska K, Zdanowicz M (2013) Medium and high substituted carboxymethyl starch: synthesis, characterization and application. Starch/Starke 65:22-33

Takahata T, Toda I, Ono H, Ohshio S, Akasaka H, Himeno S, Kokubu T, Saitoh H (2009) Detailed structural analyses of KOH activated carbon from waste coffee bean. Jpn J Appl Phys 48:117001

Yang S, Fu S, Liu H, Zhou Y, Li X (2011) Hydrogel beads based on carboxymethyl cellulose for removal heavy metal ions. J Appl Polym Sci 119:1204-1210

Yeasmin MS, Mondal MdIH (2015) Synthesis of highly substituted carboxymethyl cellulose depending on cellulose particle size. Int J Biol Macromol 80:725-731

Publisher's Note Springer Nature remains neutral with regard to jurisdictional claims in published maps and institutional affiliations. 